\title{
Periodic volcanic degassing behavior: The Mount Etna example
}

\author{
G. Tamburello, ${ }^{1}$ A. Aiuppa, ${ }^{1,2}$ A. J. S. McGonigle, ${ }^{2,3}$ P. Allard, ${ }^{4,5}$ A. Cannata, ${ }^{5}$ G. Giudice, ${ }^{2}$ \\ E. P. Kantzas, ${ }^{3}$ and T. D. Pering ${ }^{3}$ \\ Received 15 July 2013; revised 30 August 2013; accepted 30 August 2013.
}

[1] In contrast to the seismic and infrasonic energy released from quiescent and erupting volcanoes, which have long been known to manifest episodes of highly periodic behavior, the spectral properties of volcanic gas flux time series remain poorly constrained, due to a previous lack of hightemporal resolution gas-sensing techniques. Here we report on $\mathrm{SO}_{2}$ flux measurements, performed on Mount Etna with a novel UV imaging technique of unprecedented sampling frequency $(0.5 \mathrm{~Hz})$, which reveal, for the first time, a rapid periodic structure in degassing from this target. These gas flux modulations have considerable temporal variability in their characteristics and involve two period bands: $40-250$ and 500-1200 s. A notable correlation between gas flux fluctuations in the latter band and contemporaneous seismic root-mean-square values suggests that this degassing behavior may be generated by periodic bursting of rising gas bubble trains at the magma-air interface. Citation: Tamburello, G., A. Aiuppa, A. J. S. McGonigle, P. Allard, A. Cannata, G. Giudice, E. P. Kantzas, and T. D. Pering (2013), Periodic volcanic degassing behavior: The Mount Etna example, Geophys. Res. Lett., 40, doi:10.1002/grl.50924.

\section{Introduction}

[2] A variety of periodic phenomena are observed in the behavior of quiescent and erupting volcanoes. Volcanic eruptions often show cyclic trends in their rate of occurrence over a range of timescales [Chance and Kelly, 1979] and seismic and acoustic volcano monitoring signals also show systematic periodicities [Chouet, 1996; Ripepe et al., 2010]. Volatiles in magmas are likely to be the key driver here: Cycles of gas bubble accumulation and coalescence are thought to act as a recurrent trigger mechanism for explosive events [Allard et al., 2005] and periodic episodes of gas bubble rise, expansion and surface bursting are believed to generate time-varying volcano seismicity and infrasound [Harris and Ripepe, 2007].

Additional supporting information may be found in the online version of this article.

${ }^{1}$ DiSTeM, Università di Palermo, Palermo, Italy.

${ }^{2}$ Sezione di Palermo, Istituto Nazionale di Geofisica e Vulcanologia, Palermo, Italy.

${ }^{3}$ Department of Geography, University of Sheffield, Sheffield, UK.

${ }^{4}$ Institut de Physique du Globe de Paris, Paris, France.

${ }^{5}$ Sezione di Catania, Istituto Nazionale di Geofisica e Vulcanologia, Catania, Italy.

Corresponding author: G. Tamburello, DiSTeM, Universita di Palermo, via Archirafi, 36, Secondo piano (ex CFTA), Palermo IT-90123, Italy. (giancarlotamburello@gmail.com)

C2013. American Geophysical Union. All Rights Reserved. 0094-8276/13/10.1002/grl.50924

[3] That gases are released from volcanoes in a cyclic manner, e.g., as a rhythmic sequence of distinct gas pockets or "puffs", has already been indirectly implied by detection of the resultant perturbations in thermal and infrasonic energy release [Harris and Ripepe, 2007; Spampinato et al., 2012]. However, direct (e.g., from the gas records themselves) observations of periodic degassing behavior are still missing, and, with the exception of data from Erebus where cyclic trends in both gas composition [Oppenheimer et al., 2009] and $\mathrm{SO}_{2}$ flux [Boichu et al., 2010] have been recently identified, there has yet to be a robust experimental validation of this hypothesis. This paucity of information reflects a lack of hitherto available high time resolution volcanic gas flux data.

[4] A major breakthrough has recently arisen from novel UV imaging techniques which enable the remote sensing of volcanic sulphur dioxide $\left(\mathrm{SO}_{2}\right)$ gas fluxes with unprecedented temporal resolution $(\approx 0.2-1 \mathrm{~Hz})$ [Mori and Burton, 2006; Kantzas et al., 2010; Kern et al., 2010] and, hence, the study of rapid eruptive phenomena [Kazahaya et al., 2011] using gas flux data for the first time. Here we report on $0.5 \mathrm{~Hz}$ emission rate measurements performed on Mount Etna with this approach, which reveal, for the first time, a distinct periodic structure in volcanic degassing at this abundantly degassing volcano.

\section{Methodology and Results}

[5] Our measurements were performed at Mount Etna volcano, Sicily, on 14 May and 1, 2, and 4 July 2011, as well as on 12 and 13 September 2012. We used two PCsynchronized UV cameras to capture sequential images of Etna's plume (see Animation S1 in the supporting information), which were processed, as detailed in Kantzas et al. [2010], to output $\mathrm{SO}_{2}$ emission rate data at $\approx 0.5 \mathrm{~Hz}$. The measurements were made from the Pizzi Deneri Observatory, on the upper north-eastern flank of Etna (at $2800 \mathrm{~m}$ above sea level and $\approx 4 \mathrm{~km}$ from the crater terrace), by imaging emissions from the north-east crater (NEC; Figure 1a), a source of considerable open vent degassing during our observations. Indeed, the volcano's tremor source location was fixed beneath this vent at that time.

[6] In a typical UV image sequence, the $\mathrm{SO}_{2}$ degassing from Mount Etna's NEC was characterized by a succession of rhythmically released concentrated $\mathrm{SO}_{2}$ clouds (or "puffs"), spaced by tens/hundreds of seconds, and which convectively rose above the vent, before being dispersed downwind by north-easterly winds (Figure 1a). The acquired $\mathrm{SO}_{2}$ flux time series, examples of which are shown in Figures 1-3, reveal this cyclic degassing behavior for each of our measurement days, demonstrating complex spectral properties which vary according to the timescale of interest. 


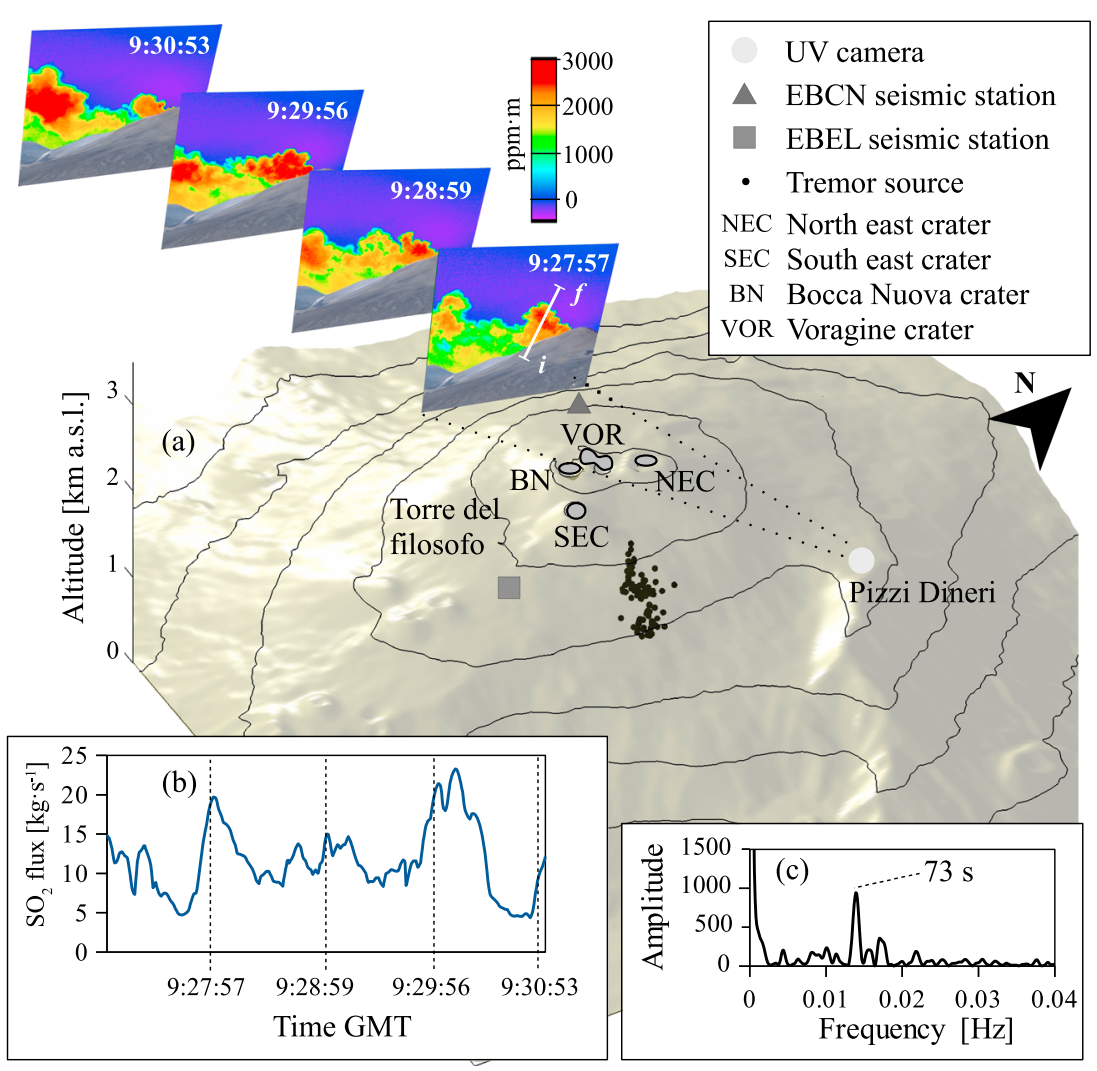

Figure 1. A digital elevation model of Mount Etna showing the four active craters (Bocca Nuova, BN; Voragine, VOR; South East Crater, SEC; North East Crater, NEC). (a) Sequence of gas puffs visible in a succession of UV camera images (pseudocolors of $\mathrm{SO}_{2}$ column densities-in ppm m - captured on 1 July 2011 from 9:27 to 9:31 local time). (b) $\mathrm{SO}_{2}$ flux time series calculated from cross section $i-f$ and (c) the corresponding fast-Fourier-transform.

[7] Over timescales of a few minutes, the gas clouds were typically observed to be emitted with regular interpuff spacing (e.g., Figure 1a), such that clear periodicity emerges in the resulting flux record (Figure 1b). This "well-behaved" degassing activity is manifested by distinct peaks in fastFourier-transform (FFT) curves of the gas flux time series (e.g., at $73 \mathrm{~s}$ in Figure $1 \mathrm{c}$ - the FFT of the data in Figure 1b). Such characteristic periodicities were commonly maintained for tens of minutes. One such example $(\approx 30 \mathrm{~min})$ record is shown in Figure 2a, demonstrating relatively constant period and amplitude in the $\mathrm{SO}_{2}$ flux oscillations throughout; the corresponding discrete-time continuous wavelet transform (Figure 2b), which shows the prevalence of each frequency in the power spectrum, reveals flux modulation with periods $\approx 150-200 \mathrm{~s}$ over most of this time frame.

[8] When explored over timescales of several hours, however, the $\mathrm{SO}_{2}$ flux time series exhibit more complex behavior, with large temporal changes in both amplitude and periodicity throughout the acquisition period, and with the manifestation of additional, longer-period oscillations. For example, the 1 July data set is shown in Figure 3, where two classes of $\mathrm{SO}_{2}$ flux variations are evident: (1) shortperiod (40-250s) modulations, analogous to those visible in Figure 1 and 2, which capture the gas puffing behavior; and (2) longer period (500-1200s) fluctuations. Both the short- and long-period components of the gas flux modulation are observed as peaks (of similar amplitude) in the fastFourier-transform (FFT) curves of the flux time series
(Figure 3d). The short-period (gas puffing) modulation demonstrates a remarkable temporal variability and, rather than having a single defined period, involves a band of periods ranging between 40 and $250 \mathrm{~s}$. Furthermore, on occasion, more than one of these periodicities can occur simultaneously. For instance, three primary categories of puffing-related degassing behavior are apparent in the periods of the wavelet transform for a zoomed $\approx 40 \mathrm{~min}$, subset of the sequence (Figure 3e): (i) episodes characterized by a stable dominant puffing frequency (e.g., from 10:04 to 10:20); (ii) phases where the puffing frequency switches, rapidly or gradually, to another mode (e.g., 10:21-10:25); and (iii) on occasion, weaker puffing activity is manifested (e.g., 10:26-10:28), such that the gas emissions' periodicity is less marked, or even disappears.

[9] These short- and long-period $\mathrm{SO}_{2}$ flux modulations were systematically observed during all the measurement days, with the most characteristic periods in flux oscillation being $\sim 150$ and $\sim 600$ s, respectively (e.g., Figure $3 \mathrm{e}$ ).

\section{Discussion and Conclusions}

[10] The spectral properties of Etna's $\mathrm{SO}_{2}$ flux, whilst being relatively complex, point clearly to the existence of flux modulation with periods in the $\sim 40-1200 \mathrm{~s}$ range, therefore providing the first reported direct experimental evidence for periodic quiescent gas release on this volcano. When considered in tandem with recent observations on Erebus volcano [Boichu et al., 2010] in Antarctica, our observations 

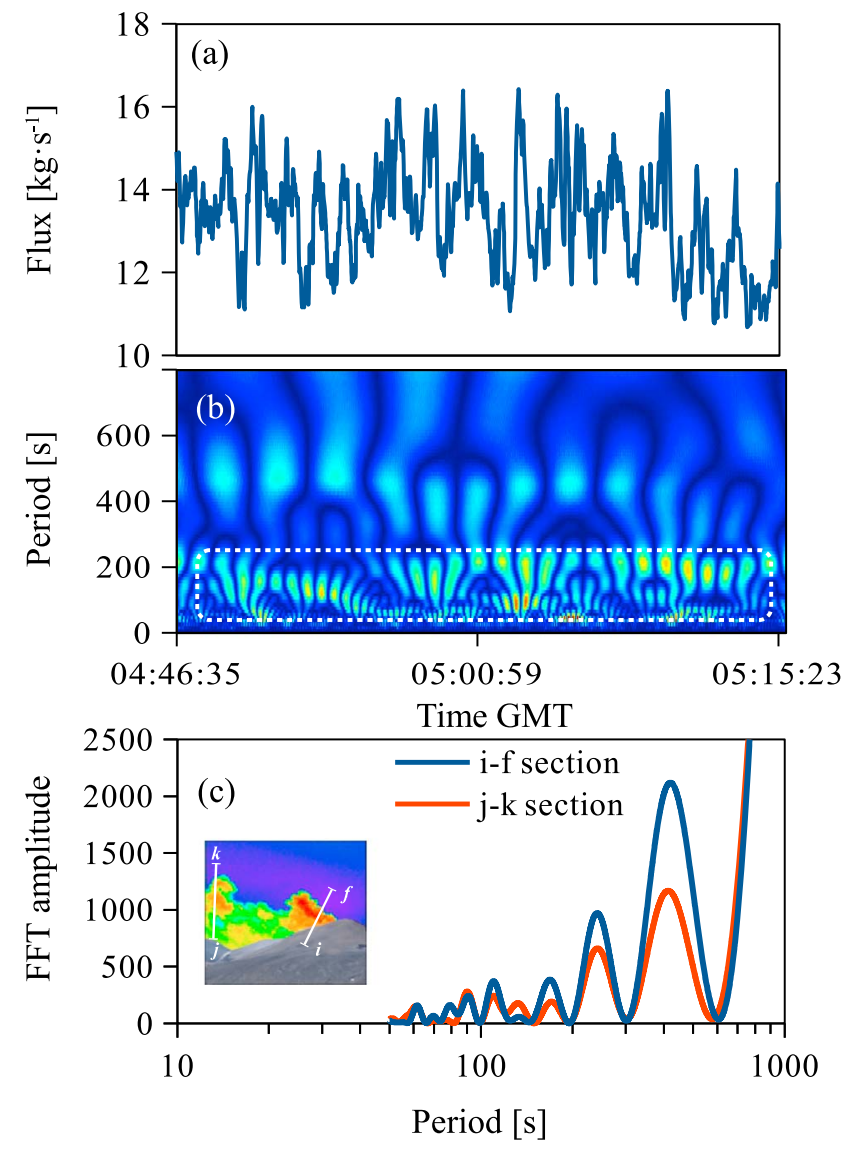

Figure 2. (a) The 30 min $\mathrm{SO}_{2}$ flux time series (from 2 July 2011) and (b) its discrete-time continuous wavelet transform (normalized), obtained using a Morlet mother wavelet (DTCMWT; this was calculated with the Wavelet Matlab ${ }^{\circledR}$ Toolbox); the Morlet wavelet type was selected in this study because it offers a best compromise between accurate time localization and high frequency resolution; (c) FFT curves for $\mathrm{SO}_{2}$ fluxes calculated from cross sections $x-y$ and $z-w$, showing a conspicuous attenuation of periodicity upon atmospheric transport.

furthermore suggest that this behavior could be a characteristic feature of open-vent volcanism worldwide.

[11] Two possible classes of mechanisms, external or volcanogenic, could be responsible for driving the observed periodic degassing.

[12] An external driver for our observed gas flux periodicity concerns non-volcanic processes e.g., those occurring after gas emission at the magma-air interface in which atmospheric transport, diffusion, turbulence, the local wind field, or even crater geometry could play a role. In consideration of these factors, we first note that the periodic $\mathrm{SO}_{2}$ degassing behavior was evident in our UV image sequences for plume cross sections immediately above the crater's rim (Figure 1), indicating that the modulations do not arise from transport effects in the free atmosphere. Furthermore, since visual observations from the crater rim confirmed that the gas puffs were already formed before exiting the crater, we argue that Kelvin-Helmholtz instabilities, caused by interaction (velocity shear) of the plume with the regional wind field, also do not play a significant role in eddy generation here.
[13] Transport effects which may be of importance within the crater itself could include turbulent diffusion or generation of eddies by convection. Turbulent diffusion could act to smooth out any generated volcanic periodicity, and the upper period limit, $t_{d}$, at which this might apply at the crater rim can be inferred after Tiesi et al. [2006]:

$$
t_{d}=(2 D t)^{0.5} / u
$$

where $D$ is the dispersion coefficient $\approx 10^{2} \mathrm{~m}^{2} \mathrm{~s}^{-1}$ in the atmosphere, $t$ is the time taken for the plume to travel from the free magma surface to the crater rim, and $u$ is the plume speed. By assuming the free magma surface to lie at the NEC crater bottom $\left(\approx 100 \mathrm{~m}\right.$ deep) and for typical rise speeds of $5-15 \mathrm{~m} \mathrm{~s}^{-1}$, $t_{d}$ values of $\approx 2-13 \mathrm{~s}$ are generated. Even for the deepest conceivable magma level, $200 \mathrm{~m}$ below the crater base, $t_{d}$ rises only to $\approx 4-21 \mathrm{~s}$, implying that this effect would not be capable of removing or creating the rather longer period oscillations we report on here, e.g., this could rule out a purely atmospheric origin of these modulations and likely supports a volcanogenic cause.

[14] The second potential in-crater process concerns largescale eddy formation, due to the plume rising convectively. Eddy formation falls into two main categories: small (Kolmogorov microscales) and large scale; here the latter is considered. The largest eddies in a flow account for most of the transport of momentum and energy. The size of these eddies is only constrained by the physical boundaries of the flow [Pope, 2000], in our case, the walls of the NEC vent. Assuming a plume cross-sectional width of $\approx 100 \mathrm{~m}$ (the diameter of the NEC), and the eddy diameters to be approximately half this value, e.g., $\approx 50 \mathrm{~m}$, a first-order estimate of the modulation period, this process might introduce a flux time series that can be inferred from the time taken for an eddy to rotate fully around one circumference. For plume speeds of $5-15 \mathrm{~m} \mathrm{~s}^{-1}$, this equates to $\approx 10-31 \mathrm{~s}$, again below the periodicities we detected.

[15] In spite of our arguments above, we still have performed some multiple flux calculation at different distances (up to $\sim 600 \mathrm{~m}$ downwind, because of the $\sim 24^{\circ}$ field of view of the camera). We find that the power spectra do attenuate-for periods $>100 \mathrm{~s}$-with increasing transport distance. This proves that atmospheric processes in the free atmosphere can only "disrupt" the puffs emitted from the vents, and that transport "cannot generate" them.

[16] On the basis of the above, we infer that our reported gas flux oscillations (of periods $>40 \mathrm{~s}$, e.g., both the longand short-period modulations) are unlikely to be a result of atmospheric transport processes. Furthermore, considering this in tandem with emerging evidence from both Erebus [Oppenheimer et al., 2009] and Etna (Pering et al., under judicial consideration), where periodic changes in released volcanic gas composition (which transport effects could not produce) have been reported, we suggest this process is more likely to be volcanogenic in origin.

[17] Indeed, cyclic release of overpressurized gas, such as in slugs or puffs, which rise through the conduit and burst at the magma-air interface, could well generate a modulation in degassing records, and volcanoes characterized by intermittent Strombolian and Vulcanian eruptions do show such behavior, with periods matched to the interexplosion time [Dalton et al., 2010; Holland et al., 2011] (e.g., $\approx 400$ s for Stromboli) [Tamburello et al., 2012]. While no visible 


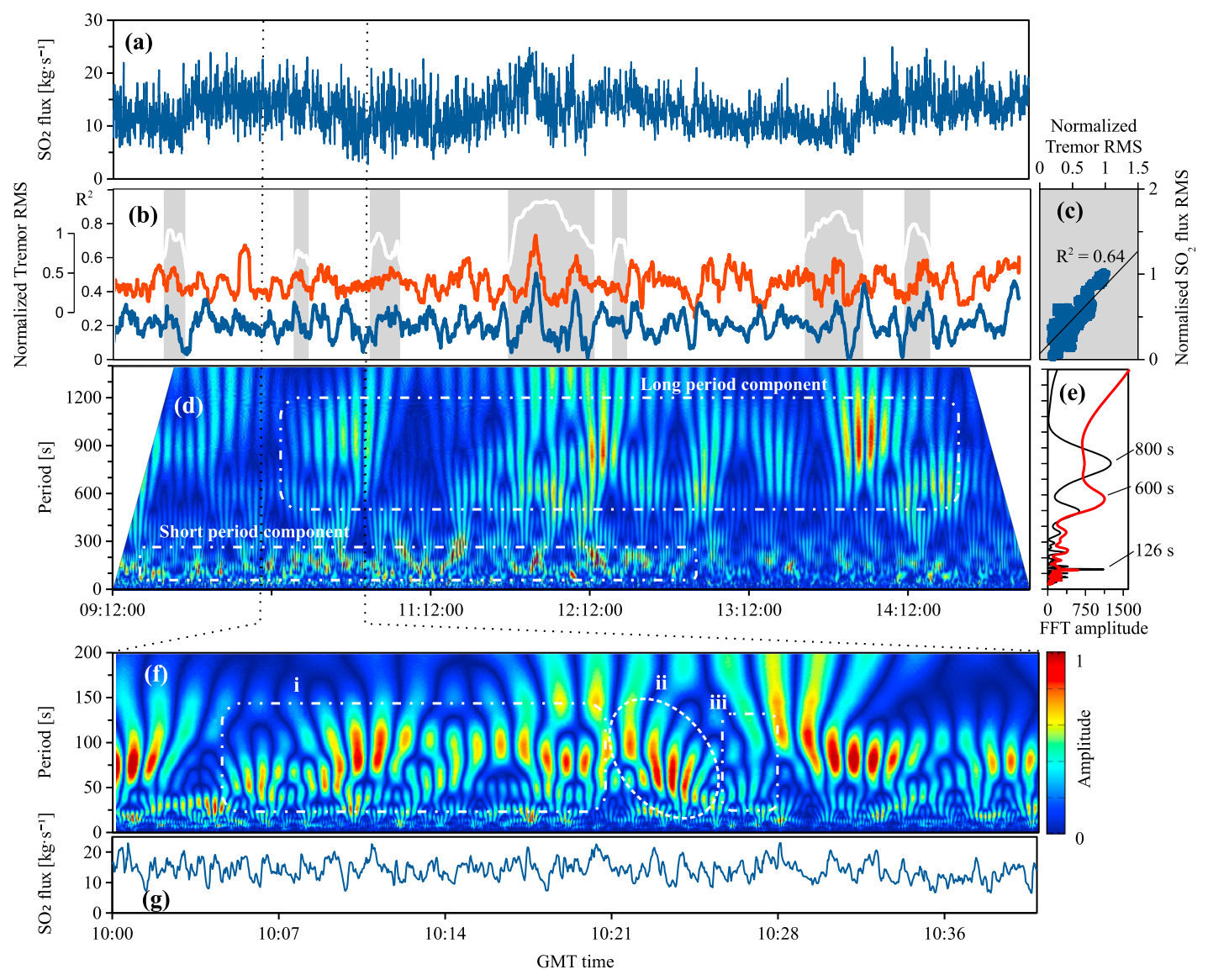

Figure 3. (a) $\mathrm{SO}_{2}$ flux time series (blue line, in $\mathrm{kg} \cdot \mathrm{s}^{-1}$ ) from the NEC on 1 July 2011; (b) normalized root-mean-squares of gas (blue) and seismic tremor (orange, $\mathrm{m} \cdot \mathrm{s}^{-1}$ ) amplitudes (calculated within a $200 \mathrm{~s}$ moving window); grey areas show the intervals in which RMSs exhibit high correlation coefficients $\left(\mathrm{R}^{2}<0.6\right.$, white line) within a window of $2000 \mathrm{~s}$; (c) $\mathrm{SO}_{2}$ flux versus normalized RMS of seismic tremor scatter diagram of the intervals within grey areas; (d) normalized DT-CMWT and (e) FFT of the $\mathrm{SO}_{2}$ flux signal (black curve). The red curve in Figure 3e is the average of normalized FFTs for all available measurement days; (f) normalized DT-CMWT of the (g) expanded view of $\mathrm{SO}_{2}$ fluxes (in blue) from 10:00 to 10:30 A.M.

explosive activity was reported at Etna during our observations, seismicity (often, a proxy for active degassing at open-vent volcanoes) typically clustered underneath NEC (Figure 1). We therefore compared our gas fluxes against the contemporaneously acquired seismic record (Figure 3). Whilst there was no significant correlation between the raw data sets, a relevant correlation $\left(\mathrm{R}^{2}>0.6\right)$ was found in the (moving window) smoothed $\mathrm{SO}_{2}$ flux and seismic rootmean-square (RMS) series, in particular, in the time intervals (shaded grey in Figure 3b), when the long-period $\mathrm{SO}_{2}$ flux modulations (500-1200 s) are more prominent in the DTCMWT (Figure 3c). We conclude, therefore, that these longer-period $\mathrm{SO}_{2}$ flux modulations (e.g., those resolved by this smoothing window RMS procedure) are indeed volcanogenic in origin and most likely related to phases of more vigorous and sustained gas bubble bursting deep inside the NEC, given the previously established relationship between intense gas spattering and volcanic tremor [Ripepe et al., 1996].

[18] Whilst the arguments against a potential atmospheric driver for our observations also apply to the short-term $\mathrm{SO}_{2}$ flux modulations (40-250s), no obvious link to seismicity was established in this case. Hence, if the generating process is indeed volcanic in nature, this would have to be "seismically silent," involving "passive" release of gas (e.g., bubbles which are not overpressurized). Convection has already been proposed as a possible cause of periodic physical perturbations in magmas [Longo et al., 2012], which, in combination with batch pulsatory supply of magma into the conduit [Oppenheimer et al., 2009], could potentially drive "passive" periodic degassing [e.g., Boichu et al., 2010]. However, given the transient behavior displayed in Figure 3, any governing process would also have to be capable of relatively rapid alteration in its frequency characteristics.

[19] We speculate, therefore, that the dynamics of gas flow, which are intrinsically more readily perturbed than those of magmas, could be stronger causal processes here, particularly given that independent ascent of gas bubbles within a silicate melt is a prerequisite for quiescent degassing. Manga [1996] suggested that gas bubbles can become arranged into horizontal layers in silicate melts, due to buoyancy forces. Such layers, if stable in the NEC conduit, could well drive the pulsed gas emissions of Figures 1-3, with each layer rising slowly enough to equilibrate pressure, prior to periodic release at the surface in a single gas puff. This would of course depend on magma velocities being small relative to the bubble rise speeds so that convective motions in the liquid could not disrupt this layering and disperse the bubbles [Manga , 1996]. We additionally argue that this process could also explain the observed temporal variations in gas flux periodicity (degassing patterns $i$ and ii in Figure 3), due to 


\section{TAMBURELLO ET AL.: PERIODIC VOLCANIC DEGASSING BEHAVIOR}

time-dependent variations in the gas layers' ascent rate, caused by heterogeneities in vesicularity and bubble dimension over the conduit height. Finally, episodes in which the $\mathrm{SO}_{2}$ flux periodicity disappears altogether (pattern iii in Figure $3 \mathrm{f}$ ) could be caused by a disruption of the rising bubble layers, perhaps due to a rapid slowing down, or increased vigor, in melt convection.

[20] Acknowledgments. The authors wish to thank C. Kern and an anonymous reviewer for their very helpful reviews of this paper. The research leading to these results has received funding from the European Research Council under the European Union's Seventh Framework Programme (FP7/ 2007/2013)/ERC grant agreement n1305377. E.P. Kantzas acknowledges support of an AXA Post Doctoral Fellowship. T.D. Pering and A.J.S. McGonigle acknowledge the support of NERC and the University of Sheffield, respectively.

[21] The Editor thanks Christoph Kern and an anonymous reviewer for their assistance in evaluating this paper.

\section{References}

Allard, P., M. Burton, and F. Muré (2005), Spectroscopic evidence for a lava fountain driven by previously accumulated magmatic gas, Nature, 433 , 407-410, doi:10.1038/nature03246.

Boichu, M., C. Oppenheimer, V. Tsanev, and P. R. Kyle (2010), High temporal resolution $\mathrm{SO}_{2}$ flux measurements at Erebus volcano, Antarctica, J. Volcanol. Geotherm. Res., 190, 325-336.

Chance, A., and P. M. Kelly (1979), An apparent periodicity in an index of volcanic activity, Nature, 280, 671-672, doi:10.1038/280671a0.

Chouet, B. A. (1996), Long-period volcano seismicity: Its source and use in eruption forecasting, Nature, 380, 309-316, doi:10.1038/380309a0.

Dalton, M., G. P. Waite, I. M. Watson, and P. Nadeau (2010), Multiparameter quantification of gas release during weak Strombolian eruptions at Pacaya Volcano, Guatemala, Geophys. Res. Lett., 37, L09303, doi:10.1029/ 2010 GL042617.

Harris, A. J. L., and M. Ripepe (2007), Synergy of multiple geophysical approaches to unravel explosive eruption conduit and source dynamics -A case study from Stromboli, Chem. Erde, 67, 1-35.

Holland, A. S. P., M. Watson, J. C. Phillips, L. Caricchi, and M. P. Dalton (2011), Degassing processes during lava dome growth: Insights from Santiaguito lava dome, Guatemala, J. Volcanol. Geotherm. Res., 202, 153-166.
Kantzas, E. P., A. J. S. McGonigle, G. Tamburello, A. Aiuppa, and R. G. Bryant (2010), Protocols for UV camera volcanic $\mathrm{SO}_{2}$ measurements, J. Volcanol. Geotherm. Res., 194, 55-60, doi:10.1016/j. jvolgeores.2010.05.003.

Kazahaya, R., T. Mori, M. Takeo, T. Ohminato, T. Urabe, and Y. Maeda (2011), Relation between single very-long-period pulses and volcanic gas emissions at Mt. Asama, Japan, Geophys. Res. Lett., 38, L11307, doi:10.1029/2011GL047555.

Kern, C., F. Kick, P. Lübcke, L. Vogel, M. Wöhrbach, and U. Platt (2010), Theoretical description of functionality, applications, and limitations of $\mathrm{SO}_{2}$ cameras for the remote sensing of volcanic plumes, Atmos. Meas. Tech., 3(3), 733-749, doi:10.5194/amt-3-733-2010.

Longo, A., P. Papale, M. Vassalli, G. Saccorotti, C. P. Montagna, A. Cassioli, S. Giudice, and E. Boschi (2012), Magma convection and mixing dynamics as a source of ultra-long-period oscillations, Bull. Volcanol., 74, 873-880, doi:10.1007/s00445-011-0570-0.

Manga, M. (1996), Waves of bubbles in basaltic magmas and lavas, J. Geophys. Res., 101, 17,457-17,465.

Mori, T., and M. Burton (2006), The $\mathrm{SO}_{2}$ camera: A simple, fast and cheap method for ground-based imaging of $\mathrm{SO}_{2}$ in volcanic plumes, Geophys. Res. Lett., 33, L24804, doi:10.1029/2006GL027916.

Oppenheimer, C., A. Lomakina, P. R. Kyle, N. G. Kingsbury, and M. Boichu (2009), Pulsatory magma supply to a phonolite lava lake, Earth Planet. Sci. Lett., 284, 392-398.

Pope, S. B. (2000), Turbulent Flows, Cambridge University Press, Cambridge, UK.

Ripepe, M., P. Poggi, T. Braun, and E. Gordeev (1996), Infrasonic waves and volcanic tremor at Stromboli, Geophys. Res. Lett., 23(2), $181-184$.

Ripepe, M., E. Marchetti, C. Bonadonna, A. J. L. Harris, L. Pioli, and G. Ulivieri (2010), Monochromatic infrasonic tremor driven by persistent degassing and convection at Villarica volcano, Chile, Geophys. Res. Lett., 37, L15303, doi:10.1029/2010GL043516.

Spampinato, L., C. Oppenheimer, A. Cannata, P. Montalto, G. Salerno, and S. Calvari (2012), On the time-scale of thermal cycles associated with open-vent degassing, Bull. Volcanol., 74(6), 1281-1292.

Tamburello, G., A. Aiuppa, E. P. Kantzas, A. J. S. McGonigle, and M. Ripepe (2012), Passive vs. active degassing modes at an open-vent volcano (Stromboli, Italy), Earth and Planet. Sci. Lett., 359, 106-116, doi:10.1016/j.eps1.2012.09.050.

Tiesi, A., M. G. Villani, M. D'Isidoro, A. J. Prata, A. Maurizi, and F. Tampieri (2006), Estimation of dispersion coefficient in the troposphere from satellite images of volcanic plumes: Application to Mt. Etna, Italy, Atmospheric Environ., 40, 628-638. 